\title{
Aplicación y uso de la web 2.0 y de las redes sociales en la comunicación científica especializada: del marketing viral al usuario activo
}

\author{
Ana Bellón Rodríguez \\ José Sixto García
}

Recibido: 3 de diciembre de 2010

Aprobado: 4 de febrero de 2011

\begin{abstract}
Resumen
Analizamos el uso que hacen las entidades científicas españolas de la web 2.0 para la difusión de sus actividades e informaciones científico-técnicas. Para ello, elegimos como marco temporal la Semana de la Ciencia, el mayor evento de comunicación científica anual que se celebra en España. Partiendo de la hipótesis de que en evento la red se convierte en el principal canal de difusión para que el público esté al corriente de las actividades, investigamos las estrategias push y pull para la captación de públicos y la ampliación del segmento-nicho, a priori demasiado circunscrito a la especialización, hasta su extensión a una audiencia más amplia y, en consecuencia, más generalista. Ha resultado especialmente interesante la aplicación que estos organismos han hecho en 2009 de la web 2.0 y de las redes sociales para incrementar sus posibilidades de comunicación mediante la aplicación de técnicas virales y de buzz, con el objetivo de que los públicos adoptasen una actitud proactiva de difusión de la ciencia entre perfiles de usuarios que comparten expectativas y aspiraciones vinculadas al mundo de la ciencia.
\end{abstract}

Palabras clave: comunicación científica, cibermedios especializados, entorno 2.0, redes sociales.

Este artículo de investigación científica y tecnológica pertenece a la investigación "Aplicación y uso de la web 2.0 y de las redes sociales en la comunicación científica especializada. Del marketing viral al usuario activo", financiada con recursos propios.

*. Consejo Superior de Investigaciones Científicas (CSIC), España. Correo electrónico: abellon@csicgalicia.cesga.es

Universidad de Santiago de Compostela, España. Correo electrónico: jose.sixto@usc.es 


\title{
Application and use of 2.0 Web and about social networks in specialized scientific communication: from viral marketing to active user
}

\begin{abstract}
This article analyzes the use of Spanish scientific entities of the 2.0 Web for spreading their scientific-technical activities and information. For this purpose, we have chosen "Science Week" as the temporal framework. "Science Week" is the most important annual scientific communication event held in Spain. Based on the hypothesis that web becomes the main spreading channel in this event for the public to be updated with activities, we do research on push and pull strategies for capturing audience and extension of the a priori segment-niche which is strongly limited to the specialization until its extension to a wider and then more general audience. Application that these organisms have made of 2.0 Web and social networks in 2009 to increase their communication possibilities by applying viral and buzz techniques has been especially interesting. This application is intended to make audiences adopt a proactive spreading attitude of science among profiles of users who share expectations and aspirations with relation to the scientific world.
\end{abstract}

Key words: scientific communication, specialized cyber-media, 2.0 environment, social networks. 


\section{Introducción}

Este artículo tiene como objetivo analizar la aplicación y el uso que hacen de la web en general y de la web 2.0 en particular los organismos que promueven actividades de divulgación y cultura científica en el marco de la Semana de la Ciencia. Como muestra analizaremos el uso que de dichos canales han hecho en el marco de la última edición de este evento, en el año 2009.

El fin último de este estudio es reflexionar sobre las posibilidades comunicativas del entorno digital para acontecimientos de carácter científico y analizar hasta qué punto con este tipo de soportes se consigue una actitud proactiva de difusión de la ciencia.

Para ello, se han consultado las webs desarrolladas en el marco de este evento y se han descrito sus principales servicios y utilidades. Además, se ha prestado especial atención a las posibilidades comunicativas con las que se encuentra el usuario de dicha web y se facilitan datos del número de usuarios de las principales redes sociales que se han dedicado a la Semana de la Ciencia 2009, lo que permite constatar la importancia de estos canales de comunicación.

\section{Cibermedios y comunicación científica especializada}

Antes de pasar al análisis de caso, sintetizaremos brevemente los principales aspectos teóricos que respaldan la investigación efectuada: los cibermedios, la comunicación científica y la especialización.

\section{1. ¿Qué son los cibermedios?}

La historia de los cibermedios, es decir, de los medios de comunicación en Internet, arranca en el año 1994 cuando comenzó a publicarse diariamente en la Internet hispana un sitio web informativo: el Boletín Oficial del Estado (Salaverría: 2005: 1). Tal y como recoge este autor, tras esta iniciativa, los principales diarios españoles comenzaron a lanzar su propia edición en Internet; a finales de la década de 1990 hicieron lo propio las radios y televisiones y a mediados del decenio se produjo una explosión de publicaciones periodísticas variopintas, nacidas en la propia red.

En la actualidad, Internet es uno de los principales sistemas de comunicación y los datos del Estudio General de Medios (EGM) constatan el progresivo incremento de las audiencias. En el siguiente gráfico reflejamos la evolución desde el año 1996 a la última oleada de febrero-marzo de 2010 :

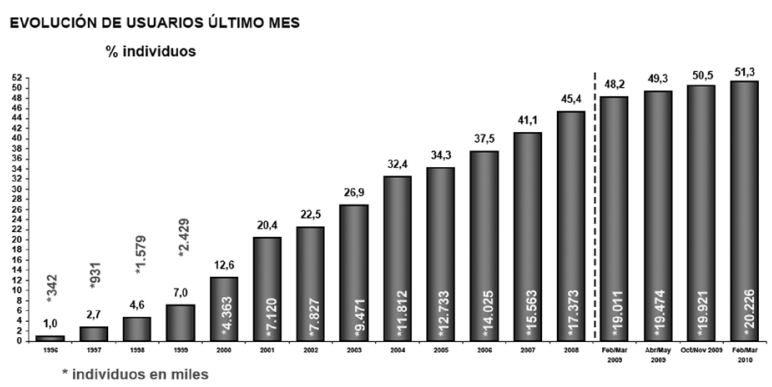

Fuente: EGM

Las razones de ese incremento se pueden encontrar precisamente en las características de los medios digitales y, por tanto, de la comunicación en red. Guillermo López (2005: 41 - 45) sintetiza dichas particularidades, así:

Ruptura del tiempo y el espacio, lo que implica instantaneidad (las redes de comunicación basadas en el lenguaje digital son capaces de llevar a cabo la transmisión de datos de una forma mucho más rápida que con los mecanismos convencionales), ruptura de la periodicidad (dichos contenidos pueden actualizarse en cualquier momento y constantemente), universalidad (los contenidos pueden ser consultados desde cualquier otro lugar conectado a la red) y capacidad de almacenamiento.

Carácter multimedia, pues se hace acopio de casi todas las formas comunicativas para integrarlas en un mismo soporte como mecanismos de expresión complementarios que dieran lugar, en última instancia, al lenguaje multimedia.

Hipertextualidad, porque el internauta cuenta con la posibilidad de convertir el consumo de información en una experiencia comunicativa 
abierta, es decir, determinar en cuanto receptor activo qué contenidos desea recibir, con qué estructuración, en qué orden, etc.

Interactividad, que puede definirse como la capacidad del receptor para tomar decisiones y regular el flujo de la información

Estas características, unidas a la ventaja que ofrece Internet respecto a otras plataformas de transmisión de contenidos en la mayor facilidad de publicación que ofrece al usuario (López, 2005: 63), hacen de la Red un sistema de comunicación idóneo y atractivo para el público general, colectivo al que se dirigen las actividades de la Semana de la Ciencia.

\subsubsection{Los cibermedios especializados}

Las páginas webs que se desarrollan en el marco de la Semana de la Ciencia se enmarcan, dentro de la categoría de cibermedios, en los de información especializada (Salaverría: 2005, 50). Dentro de este grupo, el Grupo Novos Medios de la Universidad de Santiago de Compostela (USC) ha establecido varias categorías (de información económica, política, cultural...) y el caso que nos ocupa se enmarca en los cibermedios de información científica, sanitaria y técnica, que contribuyen al crecimiento del árbol de la ciencia, (1) con la divulgación de la investigación y los descubrimientos científicos, (2) con la difusión de conocimientos sobre diversas subáreas técnicas y (3) con la preocupación por la salud y el bienestar social.

Según los estudios llevados a cabo por este grupo de investigación en el año 2005, "la fragmentación del conocimiento se cierne sobre un 40,27\% de los cibermedios existentes en España. De los 1.274 medios digitales asentados en alguna de las comunidades autónomas del Estado, 513 responden a los parámetros propios de la especialización periodística" (Salaverría: 2005. 51). De esos 513, un 6,82\% corresponde a medios especializados en ciencia, sanidad y técnica.

En relación con las páginas web de instituciones (grupo en el que se pueden enmarcar las iniciativas llevadas a cabo en el marco de la Semana de la Ciencia), López asegura que "reproducen en la Red su existencia en el mundo físico con el objetivo primordial de ofrecer un servicio público al ciudadano" (2005: 149).

\subsection{La importancia de la comunicación y divulgación científica: la especialización científica}

La difusión y comunicación de la Ciencia ha adquirido un peso notable en los últimos años debido, en parte, a la Sociedad del Conocimiento o de la Información:

Una sociedad del conocimiento debe garantizar el aprovechamiento compartido del saber, ha de poder integrar a cada uno de sus miembros y promover nuevas formas de solidaridad con las generaciones presentes y venideras. No deberían existir marginados en la sociedad del conocimiento, ya que éste es un bien público que corresponde a todos (UNESCO 17-25: 2005).

El ciudadano de a pie tiene cada vez más interés en estar informado de los avances científicos que, tarde o temprano, repercutirán en su vida. Por su parte, los científicos son conscientes de que es necesario que sus hallazgos e investigaciones crucen las fronteras de los laboratorios y de las publicaciones en las revistas científicas. Los gobiernos dedican una cantidad importante de fondos a la $\mathrm{I}+\mathrm{D}+\mathrm{i}$, por lo que es necesario que el público conozca a qué se destina esa cantidad de dinero que proviene de sus impuestos y qué efectos tendrá en su vida.

Manuel Calvo Hernando, uno de los periodistas científicos por excelencia en estos momentos en España, ha recogido en sus publicaciones y estudios al respecto una síntesis de los aspectos que explican la necesidad de acercar la ciencia al público general a través de los medios de comunicación y de la divulgación:

Nuestra vida cotidiana, nuestro presente y nuestro futuro, dependen de la ciencia y la tecnología y, a pesar de ello, la mayor parte de los ciudadanos de un país, incluidos los que consideramos "cultos", ignoran no sólo la historia de los descubrimientos que nos afectan, sino el propio contenido de tales descubrimientos (Calvo, 1997: 216). 
Según Calvo Hernández, el periodismo científico especializado es "una de las últimas y más esperanzadoras especialidades del periodismo" (1997: 12). Entre las causas que explican este hecho figura que "la actualidad informativa está cada día más impregnada de ciencia y tecnología" (1997: 17). El periodista científico ejerce de mediador entre la ciencia -o los científicos- y la sociedad para poner al servicio de la mayoría los conocimientos de la minoría. En este sentido, "la especialización tiene un doble origen, que en el fondo es el mismo: cumplir la exigencia del público e incrementar la cuota de lectores y anunciantes, constituye un objetivo único (...) La especialización, que no nació para esto, ahora sí puede decirse que constituye, o debe constituir, un factor de diferenciación, en unos momentos tan tremendamente competitivos" (1992: 49).

En estos momentos se habla con frecuencia de periodismo científico y de divulgación científica, conceptos que no son lo mismo a pesar de que sus objetivos sean coincidentes. Es necesario, por tanto, establecer unas diferencias conceptuales entre ambos términos. En primer lugar, divulgar "es transmitir al gran público, en lenguaje accesible, descodificado, informaciones científicas y tecnológicas. Sus formas son los museos, las conferencias, las bibliotecas, los cursos, las revistas, el cine, la radio, el diario, la TV, los coloquios..." (Calvo, 2005: 10). Por tanto, divulgación científica es una expresión polivalente que comprende toda la actividad de explicación y difusión de conocimientos, de la cultura y del pensamiento, con dos condiciones: la primera, que la explicación y la divulgación se hagan fuera del marco de la enseñanza oficial o equivalente; la segunda que estas explicaciones extra-escolares no tengan como objetivo formar especialistas o perfeccionarlos en su propio campo.

Sin embargo, el periodismo científico "es una especialidad informativa de nuestro tiempo, con extraordinarias perspectivas profesionales y con clara vocación de futuro" (Calvo, 1992: 23) que consiste "en divulgar la ciencia y la tecnología a través de los medios de comunicación" (1997: 16).

\section{Investigación y métodos}

\subsection{Contextualización: definición y objetivos de la Semana de la Ciencia}

La Semana de la Ciencia es el mayor evento anual de comunicación social de la ciencia y la tecnología y la iniciativa de divulgación científica más importante del año. Tiene sus orígenes en Francia en 1991 cuando Hubert Curien, ministro francés de Investigación, celebró el décimo aniversario del Ministerio abriendo sus jardines por primera vez al público con la finalidad de acercar al ciudadano parisiense la ciencia y sus protagonistas. Esta iniciativa se convirtió de este modo en precursora de lo que hoy se conoce como Semana de la Ciencia, evento de periodicidad anual que se celebra en el ámbito nacional desde el año 2002 impulsado por la Unión Europea.

El principal objetivo de este evento es fomentar la sensibilidad de la sociedad hacia las actividades de investigación científica e innovación tecnológica, y promover la cultura científica entre los ciudadanos. Como objetivos secundarios figuran acercar la ciencia al público de todas las edades, estimular el gusto por el saber científico e incentivar la participación de los ciudadanos en cuestiones científicas mediante actividades de divulgación en museos, universidades, centros de investigación, parques tecnológicos, etc.

La Semana busca, a través del trabajo de instituciones y centros de investigación, que el gran público acceda a los espacios donde se desarrolla el conocimiento científico y entre en contacto directo con los laboratorios y los investigadores. Para ello, se recurre a todo tipo de formatos: talleres, exposiciones, visitas guiadas y jornadas de puertas abiertas, encuentros entre jóvenes e investigadores, cafés científicos, debates, conferencias o espectáculos varios. Todos estos formatos constituyen iniciativas que se intentan llevar a cabo de un modo ameno, divertido, accesible, divulgativo pero sin perder el rigor científico.

En España, la Semana de la Ciencia está organizada por el Ministerio de Ciencia e Innovación, y coordinada por la Fundación Española para la Ciencia y la Tecnología (FECYT). Se celebra anualmente en el mes de noviembre y cuenta 
con la participación de las comunidades autónomas y de diversos organismos públicos, privados y universidades (UCM, CSIC, AENA, Fundación La Caixa, mNACTED...) que organizan un amplio programa de actividades para todos los públicos.

La última edición de la Semana de la Ciencia en nuestro país fue del 9 al 22 de noviembre del 2009. Contó con más de 2.000 iniciativas de divulgación científica de carácter gratuito, (talleres, conferencias, exposiciones...) organizadas por 509 entidades (museos, universidades, centros de investigación, empresas...).

La comunicación de dichas actividades a los públicos potenciales cobra un papel relevante, pues su éxito radica en que la gente asista y participe en ellas, para lo que es fundamental que estén al tanto de qué actividades se celebran y cuándo para poder asistir. Es importante, por tanto, que haya información útil y práctica, en varios soportes de comunicación (desde cartelería y material de merchandising a presencia puntual y constante en los medios de comunicación) para que el público general conozca que se está celebrando este evento en su comunidad y las opciones que cuenta para participar en él.

\subsection{Soportes de difusión}

Una vez que se han diseñado y preparado las actividades, los organismos e instituciones que participan en la Semana de la Ciencia centran sus esfuerzos en hacer llegar al público general la información de las actividades: contenidos, lugares de celebración, días, horas... Para que dichas propuestas tengan éxito y cuenten con público es fundamental que la gente esté al corriente de qué se va a celebrar, dónde y cuándo.

Se trata, además, de una obligación que los organizadores contraen con la Fundación Española para la Ciencia y la Tecnología (FECYT), entidad que financia parte de las actividades con la ayuda adicional de las comunidades autónomas y de las entidades organizadoras, y que establece en las bases de la "Convocatoria de Ayudas para el Programa de Cultura Científica y de la Innovación" (programa con el que se financian la mayor parte de los proyectos de comunicación y divulgación de la ciencia y la innovación) que los beneficiarios deberán contar con un plan de comunicación para la difusión de las actividades y registrarlas en la web http://www.actividadesaecinn.es

En esta comunicación nos centramos en los soportes de difusión a los que se dirigen estos organismos a través de un plan de comunicación y con los que se busca tener presencia e impactos en medios de comunicación. El plan de comunicación que diseñan los responsables de prensa de estos organismos con el objetivo de que los medios difundan su programa de actividades y las incluyan en agenda se canaliza fundamentalmente a través del envío puntual de notas de prensa, con las que se informa periódicamente de las actividades que se están celebrando, y a través de la difusión en la web del organismo de dichas actividades. En ocasiones, si el programa de iniciativas es amplio, se puede optar por convocar a los medios a una rueda de prensa para presentarlo a los periodistas.

Al margen de este tipo de comunicación, con el que se pueden conseguir impactos en prensa, radio, televisión y portales, hay una comunicación emergente de actualidad y de moda: la comunicación a través de la red en general y de las redes sociales en particular, temas centrales de la presente investigación. En el año 2009 la difusión en red de las actividades de la Semana de la Ciencia se realizó fundamentalmente a través de cuatro tipos de páginas webs y de las redes sociales facebook y twitter.

En el plano estatal, el evento cuenta una web propia, que se actualiza a lo largo del año cuando se produce alguna novedad significativa (fechas en las que se va a celebrar la próxima edición, actividades puntuales que se están desarrollando...). La web estatal de la Semana de la Ciencia (www.semanadelaciencia.es) es un espacio virtual de carácter oficial y con contenidos estáticos y dinámicos. Los usuarios disponen de información de los programas completos de actividades en las comunidades autónomas (fechas, horarios, lugares de celebración, participantes...), de enlaces a otras webs de interés y a las redes sociales sobre el evento. 
Dada la relevancia que tiene la Semana de la Ciencia en algunos organismos, que participan con un amplio programa de actividades y que centran sus esfuerzos y recursos divulgativos en estas fechas, se da el caso también de webs propias sobre este evento. En esta comunicación tomamos como análisis de caso la web del Consejo Superior de Investigaciones Científicas (CSIC), organismo público de investigación comprometido con la cultura científica que desarrolla tanto a lo largo del año como en la Semana actividades de divulgación en varias comunidades autónomas. La web del CSIC para la Semana de la Ciencia es http://www.semanadelaciencia.csic. es/. Aunque se mantiene abierta y accesible a lo largo del año, los contenidos dinámicos sólo se producen en los días en los que se celebra este evento.

En el ámbito autonómico, hay entidades públicas que participan tanto en el orden organizativo como en el financiador, en la Semana. Para este estudio tomamos como análisis de caso a la Dirección Xeral de I+D+i de la Consellería de Economía e Industria de la Xunta de Galicia. La web que habilitó esta entidad en el marco de la Semana de la Ciencia 2009 fue http://www.divulgacion360.org.

Al margen del programa de temática variada de actividades de divulgación, cada edición de la Semana de la Ciencia se dedica a conmemoraciones científicas. En el 2009 se conmemoró el Año Internacional de la Astronomía, para lo que se habilitó la web http://www.astronomia2009.es/ y el Año Darwin, para lo que se habilitó la web http://www.sesbe.org/darwin_day.

En cuanto al fenómeno de las redes sociales, ha sido en esta edición de 2009 cuando se expresó en todo su potencial para la difusión y comunicación de la Semana de la Ciencia. Al margen de facebook y twitter las entidades financiadoras de las actividades (FECYT en España, Dirección Xeral de I+D+i en Galicia) pusieron para ello a disposición de los organismos participantes las herramientas para hacer un entorno comunicativo más dinámico e innovador: los espacios colaborativos en Internet a través de los blogs y galería flickr.com.
Para llevar a cabo el presente estudio se han consultado y analizado las webs que se enmarcan en la comunicación y difusión de actividades de la Semana de la Ciencia. El período de consulta se ha realizado en el mes de celebración del evento (noviembre 2009) y en meses posteriores (marzo, junio).

De cada web se facilitan datos sobre: idioma, tipo de contenido, secciones, posibilidades de participación del usuario...

\subsubsection{Análisis comparativo de las webs}

a) La web estatal de la Semana de la Ciencia

La página web estatal de la Semana de la Ciencia 2009 (http://www.semanadelaciencia.es) está en castellano y cuenta con contenidos informativos, de agenda y enlaces de interés.

La home page incluye un breve texto de presentación de la Semana de la Ciencia y en el margen derecho banners de acceso al blog de la semana, facebook, twitter, agenda y flickr.com. El menú de navegación consta de 7 partes: un buscador de actividades; un buscador de las entidades participantes; prensa; comité científico, astronomía, Darwin y enlaces.

Bajo el menú de navegación está el logo de la Semana de la Ciencia, y en la parte inferior de la página, los logos de Ministerio de Ciencia e Innovación y de la Fundación Española para la Ciencia y la Tecnología. Se trata, por tanto, de una web con una fuerte presencia institucional.

En la pestaña "Buscador de actividades" el usuario accede a una página en la que puede realizar la búsqueda por fechas o por provincias. También se puede acceder a un buscador avanzado de actividades por palabra clave, tipo de actividad, temas, entidad organizadora... Pulsando en "Entidades participantes" se accede a un buscador con dos criterios: entidad organizadora o tipo de entidad.

En la sección "Prensa" el usuario puede descargar los logotipos oficiales de la Semana de la Ciencia en las cuatro lenguas oficiales del Estado; consultar el dossier de prensa del evento por comunidades autónomas o las notas de prensa que se han difundido a medios para dar a co- 
nocer las actividades y los impactos que dichas notas han generado.

En la opción "Cine Científico" se accede a una presentación de esta actividad y a una relación de las películas y documentales disponibles.

La pestaña "Astronomía" incluye una presentación del "Año Internacional de la Astronomía" y un vídeo en you tube sobre el juego del Big Bang, así como un enlace a la página dedicada a esta conmemoración.

En "Darwin" se facilita la información fundamental del "Año Darwin" y el acceso a un juego interactivo para descubrir cómo eran los continentes hace años.

Por último, en el menú de navegación se puede acceder a enlaces de interés autonómico, europeo, nacional y de anteriores ediciones. Los usuarios de esta web pueden, además, suscribirse a RSS.

En el blog de la Semana de la Ciencia en el orden estatal, al que se puede acceder desde esta web, http://www.blogsemanadelaciencia.es/, es posible consultar los post sobre este evento desde su inicio hasta su clausura. Los post constan de la información fundamental sobre las actividades: entidad organizadora, contenido, fecha de inicio y fin, datos de contacto... Además de los posts, el blog consta de una galería de fotos.

\section{b) La web del CSIC para el evento}

En el año 2009, cerca de 90 centros e institutos del CSIC en todas las comunidades autónomas programaron 47 jornadas de puertas abiertas y visitas guiadas, 97 mesas redondas y conferencias, 45 talleres experimentales y cursos, 24 exposiciones, 14 itinerarios o excursiones de carácter científico, varios certámenes y concursos, representaciones teatrales, proyecciones, cine científico, etc.

Para dar a conocer este amplio programa, el CSIC desarrolló una página web propia en el marco de este evento, la web http://www.semanadelaciencia.csic.es/, en castellano. La página principal consta de un buscador de actividades, destacados, una presentación de la participación del CSIC en la Semana y banners de acceso a la página web de FotCiencia (certamen nacional de fotografía científica promovido por el CSIC); la web de la Semana en el Centro de Ciencias Humanas y Sociales del CSIC (que organizó 30 actividades); al blog de la Casa de la Ciencia de Sevilla; a la web del Real Jardín Botánico y a información de "Contos e Coplas de Estrelas", proyecto llevado a cabo por la Delegación del CSIC en Galicia.

\section{c) La web http://www.divulgacion360.org}

Se trata de un espacio desarrollado por la Dirección Xeral de I+D+i de la Consellería de Economía e Industria de la Xunta de Galicia, entidad que financia y organiza en Galicia actividades de divulgación.

En mayo del 2009 esta entidad puso a disposición de los organismos gallegos que realizan actividades de divulgación una nueva herramienta para la puesta en común de la divulgación y la comunicación de la ciencia, la tecnología y la innovación en Galicia: la página web http://www. divulgacion360.org, en gallego.

La web nació con el objetivo de servir de punto de encuentro e información para las entidades que organizan actividades de divulgación y también para el público interesado en acudir. El contenido incluía información de las actividades de divulgación que se celebraban en Galicia, enlaces de interés, recursos de divulgación, tablón de anuncios para el intercambio de avisos y noticias, así como espacios dedicados a las conmemoraciones científicas.

Esta página ha estado en funcionamiento hasta hace unos meses cuando, a raíz del cambio de gobierno en Galicia, se redujo el personal del Programa de Comunicación e Sensibilización Social do Plan Galego de I+D+i, encargado de su mantenimiento.

Las entidades organizadoras de actividades cubrían a través de la web una serie de formularios para enviar las actividades que posteriormente se subían a http://www.divulgacion360.org

\section{d) Las webs de las conmemoraciones}

En el año 2009 se conmemoró, en el marco de la Semana de la Ciencia, el Año Internacional 
de la Astronomía y el Año Darwin, eventos que contaron con su correspondiente página web.

La página del Año Internacional de la Astronomía (http://www.astronomia2009.es/) cuenta con un amplio abanico de posibilidades en el menú de navegación:

1. Pestaña sobre el Año Internacional de la Astronomía.

2. Listado de actividades.

3. Sala de prensa y noticias sobre el AIA.

4. Proyectos pilares y proyectos de ámbito nacional.

5. El tema del mes.

6. Una zona de artículos de divulgación sobre temas de astronomía.

7. Astroeduca-t, espacio dedicado a profesores y alumnos con material educativo.

8. Astronomía adaptada, espacio con iniciativas para acercar la astronomía a personas con discapacidad.

9. Blogs cósmicos.

10. Astrodirectorio: enlaces de interés.

11. Glosario astronómico con más de 100 términos.

12. Novedades

En la página principal hay banners de acceso a actividades, ceremonias, astronomía en viñeta y un tema del mes e imagen del día destacada. Además, la web dispone de un buscador de artículos por público objetivo y ofrece la posibilidad de registrarse y de suscribirse a las novedades.

Para la conmemoración del Año Darwin, la Sociedad Española de Biología Evolutiva realizó la web http://www.sesbe.org/darwin_day. La página principal incluye a modo de destacado los eventos y destacados sobre Darwin en el año 2008 y 2009 y en el margen derecho banners de acceso a recursos para docentes, portadas de libros sobre Darwin y a la revista Evolución. En este último caso, el usuario puede descargar los últimos números de la publicación.

El menú de navegación consta de seis secciones (SESBE, Descargar, Navegar, Eventos, Mapa de Visitas, Contacto) con sus correspondientes subsecciones. En SESBE se puede con- sultar información sobre la Sociedad, la Biología Evolutiva, la web y los miembros de SESBE; en Descargar el usuario puede bajarse la revista Evolución, temas y tesis sobre Biología Evolutiva; en Navegar se puede buscar información sobre libros, revistas, vídeos, curiosidades, etc.; en Eventos se pueden consultar los últimos y los recientes; en Mapa de Visitas se puede consultar el acceso a la web desde todo el mundo en las últimas 24 horas y, por último, en Contacto se pueden encontrar datos del SESBE, listas de BioEve y con webmaster.

\subsection{La Semana de la Ciencia 2009 en la web 2.0: tipologías usadas y participación activa}

Si algo caracterizó la Semana de la Ciencia 2009 en el campo comunicativo fue su desembarco en la web 2.0.

En Galicia la iniciativa estuvo promovida por la Dirección Xeral de I+D+i de la Consellería de Economía e Industria, entidad que puso a disposición de los organizadores de actividades herramientas para hacer el entorno comunicativo más dinámico e innovador: las redes sociales y los espacios colaborativos en Internet.

Los organizadores contaron con manuales y claves comunes para gestionar los contenidos de la entidad en relación con la Semana de la Ciencia en cuatro canales 2.0:

Blog: para contar qué actividades se tiene previsto realizar en la Semana de la Ciencia y qué expectativas se manejan para, una vez terminadas, comentar en otro post la experiencia.

Red social de formato microblogging (Twitter): para anunciar en pocas palabras (como máximo 140 caracteres) las actividades, de un modo rápido y efectivo.

Galería Flickr para publicar, compartir y comentar fotografías: parte de los eventos de la Semana de la Ciencia que se realizaron en Galicia quedaron registrados gráficamente en esta galería.

Plataforma Slideshare: para colgar presentaciones digitales en el transcurso de las actividades. 
En España, la Semana de la Ciencia se puede seguir en facebook, página que cuenta con 450 seguidores. La mayor parte de las publicaciones se enmarcan en los días de celebración del evento. Hay fotos de actividades varias y notas sobre la Semana. También se puede seguir en Twitter, espacio que cuenta con 133 tweets, 109 seguidores y 10 listas.

\section{Conclusiones finales}

Las características intrínsecas de Internet como la ruptura del tiempo y del espacio, su carácter multimedia, la hipertextualidad o la interactividad lo convierten en un soporte idóneo para que los organismos promotores de actividades científicas puedan difundirlas a un público potencial de carácter general. Un ejemplo lo constituye la Semana de la Ciencia, que tuvo en la red uno de sus principales canales para la difusión y promoción de sus actividades.

Hasta ahora el proceso de comunicación en este tipo de eventos era sistemático, consolidado y repetitivo: las entidades creaban, difundían su mensaje e intentaban que lo recibiese el mayor número posible de receptores. Sin embargo, con la irrupción de las nuevas tecnologías, especialmente de la web 2.0, los usuarios han pasado de simples receptores a participantes implicados y activos en este tipo de actividades, en la medida en que ya no sólo consumen contenido, sino que lo crean, lo comparten, lo valoran y lo difunden.

De la actitud pasiva hemos llegado a la estrategia proactiva de iniciativa personal, y no sólo institucional. Ahora instituciones y usuarios crean contenido en paralelo y el éxito de las publicaciones de los organismos está condicionado en gran parte por la actividad participante y difusores de los públicos. La información se propaga utilizando mecanismos virales, análogos a las estrategias de marketing viral, mediante relacio- nes establecidas entre los miembros de una red social que actúan de válvulas propagadoras de contenido entre su rama de relaciones.

Son los propios usuarios 2.0 quienes eligen lo que les interesa, de manera que las estrategias push cobran fuerza al tiempo que disminuyen los enfoques pull, pues son ellos los que actúan de promotores de los productos que les merecen su atención sin necesidad de que ningún factor externo ejerza ninguna presión: comentan en blogs y en las redes sociales, aportan impresiones en los formatos de microblogging o de fotografías, o se unen a grupos o páginas de eventos.

Por todo ello, la comunicación científica no debe realizarse sin tener en cuenta estas nuevas potencialidades digitales y, sobre todo, sin acatar las nuevas conductas de los usuarios, pues, en definitiva, es a ellos a quienes va dirigida y de quienes se espera receptividad. El feedback se ha aumentado, la personalización one to one se ha mejorado, la participación ha surgido y la red social de propagación viral es el mejor ámbito de difusión que hemos conocido.

\section{Referencias bibliográficas}

Calvo Hernando, M. (1997): Manual de periodismo científico. Barcelona: Bosch Comunicación.

Calvo Hernando, M. (2005): Periodismo científico y divulgación de la ciencia. Madrid: Asociación de Autores Científico-Técnicos y Académicos.

López, G. (2005): Modelos de comunicación en Internet. Valencia: Tirant Lo Blanch.

Salaverría, R. (Coord.) (2005): Cibermedios. El impacto de Internet en los medios de comunicación en España. Sevilla: Comunicación Social Ediciones y Publicaciones, Colección Periodística 15 ..

UNESCO (2005) Informe Mundial de la UNESCO "Hacia las Sociedades del Conocimiento". París: Ediciones UNESCO. 